\title{
Factors associated with breast self-examination among Malaysian women teachers
}

P. Parsa, ${ }^{7}$ M. Kandiah ${ }^{2}$ and N. Parsa ${ }^{3}$

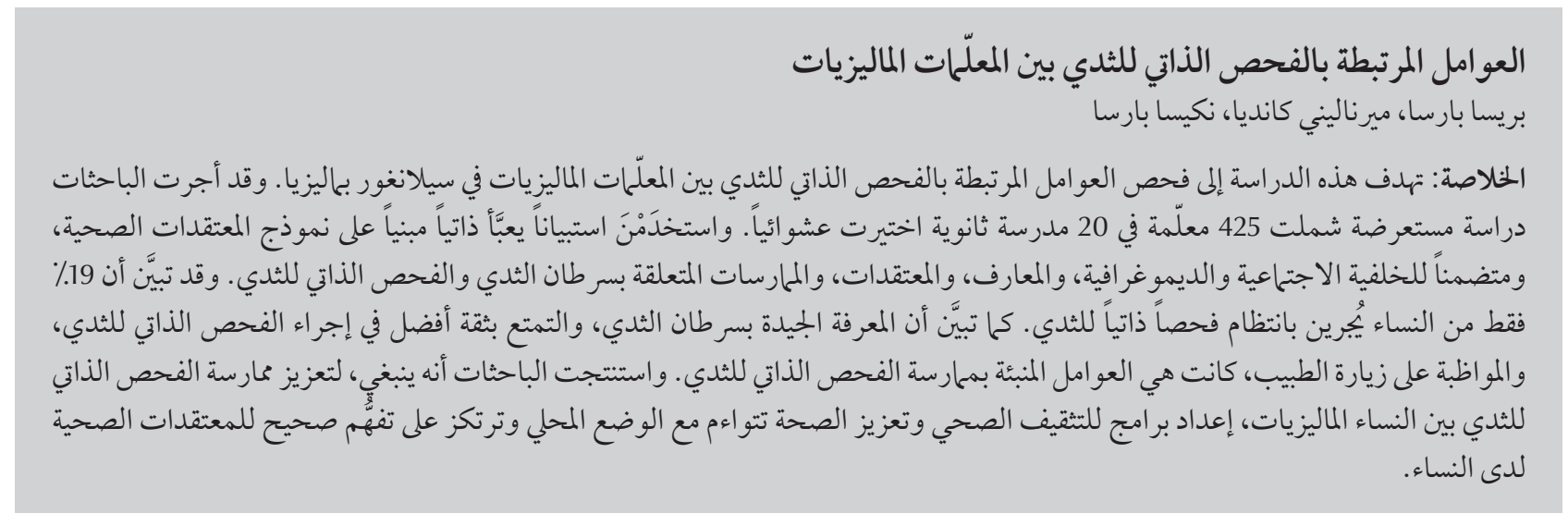

ABSTRACT The purpose of this study was to examine factors related to breast self-examination (BSE) among teachers in Selangor, Malaysia. A cross-sectional study was conducted among 425 female teachers in 20 randomly selected secondary schools. A self-administered questionnaire based on the health belief model was used, including sociodemographic background and knowledge, beliefs and practices about breast cancer and BSE. Only 19\% of the women performed BSE on a regular basis. Higher knowledge about breast cancer, greater confidence in performing BSE and regular visits to a physician were significant predictors for practising BSE. To promote BSE practice among Malaysian women, tailored health education and health promotion programmes should be developed based on a specific understanding of women's health beliefs.

\section{Facteurs associés à l'auto-examen des seins chez des enseignantes malaisiennes}

RÉSUMÉ La présente étude avait pour objectif de rechercher les facteurs liés à l'auto-examen des seins chez des enseignantes de l'État de Selangor (Malaisie). Une étude transversale a été conduite auprès de 425 enseignantes travaillant dans vingt établissements d'enseignement secondaire sélectionnés aléatoirement. Un autoquestionnaire reposant sur un modèle de croyances relatives à la santé a été utilisé, couvrant les informations sociodémographiques des répondantes, leurs connaissances et croyances au sujet du cancer du sein et de l'autoexamen des seins et leurs pratiques en la matière. Seules 19 \% des femmes pratiquaient l'auto-examen des seins de manière régulière. Une meilleure connaissance du cancer du sein, une confiance élevée dans la pratique de l'auto-examen des seins et des visites régulières chez un médecin étaient des facteurs prédictifs importants pour la pratique de cet auto-examen. Afin de promouvoir l'auto-examen des seins chez les femmes malaisiennes, des programmes sur mesure d'éducation sanitaire et de promotion de la santé doivent être élaborés en tenant compte des croyances des femmes en matière de santé.

${ }^{7}$ Child and Maternal Health Research Centre and Health Science Research Centre, Department of Maternal and Child Health, Hamedan University of Medicine and Health Sciences, Hamedan, Islamic Republic of Iran (Correspondence to P. Parsa: pparsa2003@yahoo.com).

${ }^{2}$ Department of Nutrition and Dietetics, Faculty of Medicine and Health Sciences; ${ }^{3}$ Department of Psychology, Faculty of Human Ecology, Universiti Putra Malaysia, Serdang, Malaysia.

Received: 12/07/09; accepted: 29/10/09 


\section{Introduction}

According to a recent report of the Malaysian cancer registry, 1 out every 19 Malaysian women has a chance of getting breast cancer in her lifetime, and more than 4000 new cases of breast cancer are diagnosed every year. Breast cancer is currently the most common female cancer in Malaysia, accounting for $30.4 \%$ of all cancers diagnosed among women [1]. Early detection and effective treatment are important to reduce morbidity and mortality due to breast cancer. Breast self-examination (BSE), mammography and clinical breast examination are believed to be appropriate and effective methods of ensuring early detection of breast cancer. Although the effectiveness of BSE as a breast cancer screening method is controversial [2-4], the American Cancer Society [2] and the Ministry in Health of Malaysia [5] encourage women to be aware of how their breasts look and feel so they will be able to recognize any changes and report them promptly to their clinicians.

Despite the effectiveness of breast cancer screening behaviours in reducing mortality, research findings indicate that screening rates remain low. In studies of community samples of diverse groups of women in the United States of America (USA), the rates for performing monthly BSE ranged from $29 \%$ to $63 \%$ $[6,7]$. Similar findings were reported in studies in Canada [8], Taiwan [9], Jordan [10] and Turkey [11]. The national health morbidity survey showed that $34 \%$ of women above age 20 years performed BSE but the frequency of performance was not studied [12].

In this study the health belief model [13-15] was used as the theoretical framework to examine variables related to BSE use. In previous studies, performing regular BSE has been associated with health belief model variables such as perceived susceptibility to breast cancer, seriousness of breast cancer, benefits and barriers to screening, confidence and health motivation [1-11,14-18]. Socioeconomic status, level of education, referral from a physician, knowledge, health insurance coverage and family history of breast cancer have also been associated with the practice of BSE $[6,10,11,19,20]$.

The purpose of the current study was to identify the rate of practising BSE and factors related to BSE screening behaviour in a sample of well educated Malaysian women. Understanding Malaysian women's health beliefs related to breast cancer screening behaviours will help health care professionals to choose more effective health education programmes and potentially to increase women's screening practices.

\section{Methods}

A cross-sectional study was carried out among female secondary-school teachers in the state of Selangor, Malaysia, between January and April 2006.

\section{Sample}

A multi-stage random sampling method was used to select the 20 secondary schools. A total of 425 teachers met the inclusion criteria and gave informed consent to participate in the study. The participants eligible for the study met the following criteria: age $23-56$ years (age range of working female teachers currently in employment up to retirement), no history of breast cancer or any other cancers, not pregnant or breastfeeding. This study obtained approval from the Ministry of Education of Malaysia.

\section{Data collection}

A questionnaire was developed by the authors based on an extensive review of the literature. The questionnaire obtained information on participants' sociodemographic characteristics; cancer-related history; and knowledge, beliefs and behaviours concerning breast cancer and BSE. Sociodemographic variables included: age, current marital status, education level, income level, ethnicity, religion and health insurance coverage. Cancer-related questions included: having regular health checkups with a physician (yes/no), previous breast disease (yes/no) and family history of breast cancer (yes/no).

Breast cancer knowledge questions (yes/no response) included: having ever heard/read about breast cancer screening tests; sources of information; and 43 knowledge questions on incidence (3 items), symptoms ( 7 items), risk factors of breast cancer (15 items) and screening tests (18 items). A score of 1 was given for a correct answer and 0 for incorrect. The maximum score for knowledge was 43 (100\%) and the minimum score was $0(0 \%)$. More description of the development of the knowledge scale may be found in another published paper [21].

The section about beliefs had 42 questions that were self-reported measures with 6 scales: susceptibility to breast cancer (5 items), seriousness of breast cancer ( 7 items), benefits of BSE (6 items), barriers to performing BSE (6 items), confidence in their ability to perform BSE (11 items) and health motivation (7 items). All the items had 5 response choices ranging from strongly disagree (1 point) to strongly agree (5 points). All scales were positively related to screening behaviours, except for barriers, which were negatively associated.

The reliability of the knowledge and belief subscales ranged from 0.73 to 0.91 , indicating good levels of internal consistency [22]. Factor analysis with principal components was carried out to assess the construct validity of the scales and was found to be acceptable. A detailed description of the translation and adaptation of Champion's health belief model scale can be found in another published article [23].

BSE behaviour was measured by self-reported responses to questions about: ever having carried out BSE; frequency, technique, etc.; and reasons for reluctance to practise BSE. 
The Malay version of the instrument was pretested on 30 female teachers to check the clarity of the items.

\section{Analysis}

The women were categorized into 2 groups: those who reported that they performed BSE and those who did not. Independent $t$-test was used to determine differences between the 2 groups. The chi-squared test was used to examine the association between categorical variables and BSE. A logistic regression analysis was conducted to identify the extent to which variables significantly predicted BSE behaviour. In all tests, the level of significance was set at $P<0.05$.

\section{Results}

\section{General characteristics of the subjects}

The mean age of respondents was 37.2 (SD 7.2), range 23 to 56 years. Most of them were married, of Muslim religion and Malay ethnic origin. Nearly all of them had a university degree and around one-fifth had no medical insurance. Most teachers had less than 20 years teaching experience. Among the total sample a family history of breast cancer was recorded by 36 respondents (9\%) and only 11 (3\%) indicated that they had a personal history of breast disease (Table 1).

\section{Practice, intention to practice, and sources of information}

Although $90 \%$ of the participants reported that they had heard about BSE, only 230/425 (54\%) had ever performed BSE. Of these 19\% stated that they performed BSE on a regular monthly basis; others reported performing BSE every 2-3 months (11\%) or occasionally $(25 \%)$.

When asked about their intention to practise BSE in the coming year, $80 \%$ of them said that they would consider examining themselves regularly. The most common reason for not doing breast cancer screening was a lack of knowledge, followed by belief that is was time-consuming or that BSE was not needed if one was in good health.

Magazines and television programmes were identified as the main sources of information on breast cancer and BSE by $95 \%$ and $83 \%$ of the participants, respectively. Printed materials (67\%), friends (52\%) and health professionals (46\%) were mentioned as other sources of information on breast cancer and BSE.

\section{Participants' health beliefs and knowledge on breast cancer and screening}

Average responses to the items on the 6 belief scales and the 4 knowledge scales are summarized in Table 2 . Significant differences between those who performed BSE and those who did not were observed for the total knowledge score $(P<0.01)$ as well as for the items of knowledge about symptoms of breast cancer $(P<0.01)$, risk factors of breast cancer $(P<0.01)$ and screening methods $(P<0.01)$. There were no significant differences between the 2 groups for knowledge about breast cancer incidence $(P=0.290)$.

Concerning belief scores and performing BSE, significant differences between groups were observed for total beliefs $(P<0.001)$. Women who performed BSE had greater confidence $(P<0.001)$ and health motivation $(P<0.001)$ and lower barriers to performing BSE $(P<0.001)$ than those who did not. There were no significant differences between the 2 groups for beliefs about susceptibility to breast cancer $(P=0.204)$, seriousness $(P=0.355)$ and the benefits of BSE $(P=0.068)$.

\section{Factors associated with BSE}

As shown in Table 1, significant associations were identified between performing BSE and income level $(P=0.019)$ and having regular checkups with the physician $(P<0.001)$. Family history of breast cancer, history of breast disease, marital status, menstruation status, age, education level, ethnicity, religion, teaching experience, health insurance, ever heard about breast cancer and perceived health status were not significantly related to performing BSE.

Table 3 shows the logistic regression model for predicting BSE performance from the sociodemographic variables and the knowledge and belief scales. This model was a good model for prediction of BSE and it explained $27 \%$ of the variance in BSE performance (Nagelkerke $R^{2}=0.27, \chi^{2}=82.49, \mathrm{df}=$ $24, P<0.001)$. The logistic regression analysis identified 3 variables with significant odds ratios (OR). Women who reported having regular check-ups with a physician were over 3 times more likely to perform BSE than those who had not $(\mathrm{OR}=3.64,95 \% \mathrm{CI}: 1.82-7.27)$. Women with greater knowledge about breast cancer and screening methods $(\mathrm{OR}=1.08,95 \% \mathrm{CI}: 1.02-1.13)$ and confidence in their ability to do BSE $(\mathrm{OR}=1.06,95 \% \mathrm{CI}: 1.00-1.12)$ were also more likely to perform BSE.

Women who had perceived good health status (OR $=4.34,95 \%$ CI: 0.66 28.33), a family history of breast cancer $(\mathrm{OR}=2.49,95 \%$ CI: 0.92-6.71), ever undergone clinical breast examination (OR $=1.90,95 \%$ CI: 0.98-3.66), ever heard about BSE (OR $=1.88,95 \% \mathrm{CI}$ : $0.21-16.78)$ and married $(\mathrm{OR}=1.28$, 95\% CI: 0.46-3.53) were somewhat more likely to perform BSE than who had not. However, these factors reached the accepted level of significance $(P$ $<0.05)$. The remaining belief scales (perceived susceptibility for breast cancer, seriousness of breast cancer, benefits of BSE, barriers to BSE and health motivation) were also not significant predictors for BSE performance.

\section{Discussion}

The findings of this study have shown that teachers in Malaysia had a low rate of practice of BSE (only 19\% performed 


\begin{tabular}{|c|c|c|c|c|c|c|}
\hline \multirow[t]{2}{*}{ Characteristic } & \multicolumn{2}{|c|}{$\begin{array}{l}\text { Performing BSE } \\
\quad(n=230)\end{array}$} & \multicolumn{2}{|c|}{$\begin{array}{l}\text { Not performing BSE } \\
\qquad(n=195)\end{array}$} & \multirow[t]{2}{*}{$\chi^{2}$-test } & \multirow[t]{2}{*}{$P$-value } \\
\hline & No. & $\%$ & No. & $\%$ & & \\
\hline \multicolumn{7}{|l|}{ Age (years) } \\
\hline 20-30 & 42 & 17.8 & 38 & 19.3 & 5.190 & 0.158 \\
\hline $31-40$ & 116 & 51.1 & 89 & 45.3 & & \\
\hline $41-50$ & 64 & 28.0 & 53 & 27.6 & & \\
\hline$>51$ & 8 & 3.1 & 15 & 7.8 & & \\
\hline \multicolumn{7}{|l|}{ Marital status } \\
\hline Married & 207 & 90.0 & 171 & 87.7 & 0.571 & 0.450 \\
\hline Single & 23 & 10.0 & 24 & 12.3 & & \\
\hline \multicolumn{7}{|l|}{ Educational status } \\
\hline Diploma & 15 & 6.1 & 15 & 7.7 & 2.230 & 0.332 \\
\hline Degree & 208 & 90.8 & 169 & 86.7 & & \\
\hline Postgraduate & 7 & 3.1 & 11 & 5.6 & & \\
\hline \multicolumn{7}{|l|}{ Ethnicity } \\
\hline Malay & 199 & 87.2 & 157 & 80.6 & 4.596 & 0.204 \\
\hline Indian & 11 & 4.4 & 16 & 8.1 & & \\
\hline Chinese & 20 & 8.3 & 22 & 11.3 & & \\
\hline \multicolumn{7}{|l|}{ Religion } \\
\hline Muslim & 203 & 87.7 & 159 & 81.7 & 5.346 & 0.254 \\
\hline Buddhist & 14 & 6.1 & 14 & 7.0 & & \\
\hline Hindu & 8 & 3.5 & 15 & 7.5 & & \\
\hline Christian & 5 & 2.2 & 7 & 3.8 & & \\
\hline \multicolumn{7}{|l|}{ Menstruation status } \\
\hline Premenopause & 216 & 94.3 & 183 & 94.1 & 0.047 & 0.977 \\
\hline Postmenopause & 14 & 5.7 & 12 & 6.0 & & \\
\hline \multicolumn{7}{|l|}{ Income level (RM) } \\
\hline Low $(<3000)$ & 28 & 12.0 & 31 & 16.0 & 7.940 & 0.019 \\
\hline Moderate (3000-5000) & 96 & 42.0 & 103 & 52.5 & & \\
\hline Good $(>5000)$ & 106 & 46.0 & 61 & 31.5 & & \\
\hline \multicolumn{7}{|l|}{ Health insurance coverage } \\
\hline No & 45 & 19.6 & 41 & 21.0 & 0.139 & 0.709 \\
\hline Yes & 185 & 80.4 & 154 & 79.0 & & \\
\hline \multicolumn{7}{|c|}{ Having regular health check-ups with physician } \\
\hline Yes & 66 & 28.7 & 30 & 15.4 & 10.693 & \\
\hline No & 164 & 71.3 & 165 & 84.6 & & 0.001 \\
\hline \multicolumn{7}{|c|}{ Family history of breast cancer } \\
\hline Yes & 22 & 9.6 & 14 & 7.2 & 0.775 & 0.379 \\
\hline No & 208 & 90.4 & 181 & 92.8 & & \\
\hline \multicolumn{7}{|c|}{ Personal history of breast disease } \\
\hline Yes & 7 & 3.0 & 4 & 2.2 & 0.319 & 0.573 \\
\hline No & 223 & 97.0 & 191 & 97.8 & & \\
\hline \multicolumn{7}{|c|}{ Ever heard/read about breast cancer and BSE } \\
\hline Yes & 223 & 97.0 & 183 & 93.8 & 2.391 & 0.122 \\
\hline No & 7 & 3.0 & 12 & 6.2 & & \\
\hline \multicolumn{7}{|l|}{ Perceived health status } \\
\hline Good & 97 & 42.4 & 73 & 37.8 & 1.17 & 0.556 \\
\hline Satisfied & 129 & 55.9 & 117 & 59.5 & & \\
\hline Poor & 4 & 1.7 & 5 & 2.7 & & \\
\hline
\end{tabular}

$R M=$ Malaysian ringgit 


\begin{tabular}{|c|c|c|c|c|c|c|c|}
\hline \multirow[t]{2}{*}{ Variable } & \multicolumn{2}{|c|}{$\begin{array}{l}\text { Performing BSE } \\
\quad(n=230)\end{array}$} & \multicolumn{2}{|c|}{$\begin{array}{l}\text { Not performing BSE } \\
\qquad(n=195)\end{array}$} & \multirow[t]{2}{*}{ Range } & \multirow[t]{2}{*}{$t$-test } & \multirow[t]{2}{*}{$P$-value } \\
\hline & $\begin{array}{l}\text { Mean } \\
\text { score }\end{array}$ & SD & $\begin{array}{l}\text { Mean } \\
\text { score }\end{array}$ & SD & & & \\
\hline \multicolumn{8}{|l|}{ Knowledge } \\
\hline Incidence knowledge & 1.98 & 0.84 & 1.80 & 0.87 & $1-3$ & 2.197 & 0.290 \\
\hline Symptom knowledge & 2.75 & 1.22 & 2.18 & 1.34 & $1-7$ & 4.488 & 0.001 \\
\hline Risk factor knowledge & 6.43 & 2.57 & 5.50 & 2.55 & $1-15$ & 3.668 & 0.001 \\
\hline Screening knowledge & 10.59 & 2.46 & 9.00 & 3.41 & $1-18$ & 5.500 & 0.001 \\
\hline Total knowledge & 21.77 & 5.18 & 18.55 & 6.28 & $1-43$ & 5.702 & 0.001 \\
\hline \multicolumn{8}{|l|}{ Beliefs } \\
\hline $\begin{array}{l}\text { Susceptibility to breast } \\
\text { cancer }\end{array}$ & 2.39 & 0.75 & 2.29 & 0.84 & $1-5$ & 1.270 & 0.204 \\
\hline Seriousness of breast cancer & 3.46 & 0.70 & 3.39 & 0.77 & $1-5$ & 0.926 & 0.355 \\
\hline Benefits of BSE & 3.89 & 0.50 & 3.79 & 0.62 & $1-5$ & 1.829 & 0.068 \\
\hline Barriers to BSE & 3.66 & 0.63 & 3.87 & 0.56 & $1-5$ & 3.423 & 0.001 \\
\hline $\begin{array}{l}\text { Confidence in performing } \\
\text { BSE }\end{array}$ & 3.49 & 0.46 & 3.21 & 0.53 & $1-5$ & 5.758 & 0.001 \\
\hline Health motivation & 3.98 & 0.50 & 3.77 & 0.51 & $1-5$ & 4.103 & 0.001 \\
\hline Total beliefs & 3.51 & 0.23 & 3.23 & 0.30 & $1-5$ & 6.116 & 0.001 \\
\hline
\end{tabular}

$S D=$ standard deviation .

BSE monthly). Similarly, the rate of regular performance of BSE among female teachers was reported to be $6 \%$ in the Islamic Republic of Iran [24], 7\% in Jordan [10] and 11\% in Egypt [25]. The higher rate of BSE performance in our study may be attributed to teachers' awareness about the risk of breast cancer in Malaysia and their exposure to media information about breast cancer and screening methods. Most of our educated women had heard or read about breast cancer but only a few performed BSE monthly. Consistent with this, Rashidi and Rajarm reported that $85 \%$ of women of Middle East origin had heard of breast cancer screening but $74 \%$ had never performed BSE [26].

In the analysis of factors associated with performing BSE, having regular health check-ups with a physician was significantly associated with BSE performance. Several researchers have reported on the role of physicians and health care providers in educating and encouraging women to carry out BSE $[10,11,27,28]$. Routine breast checks by providers may help women to feel at ease and become more confident about performing BSE, and may provide knowledge about its benefits.

Women with higher levels of knowledge about breast cancer symptoms and screening demonstrated higher performance rates of BSE. This is consistent with previous findings suggesting that knowledge of breast cancer screening is an important facilitator for breast cancer screening behaviours $[6,29,30]$. Knowing the steps required, understanding the required frequency of BSE and being aware of the normal anatomy of their own breasts are issues that can be addressed by health personnel in assisting women to do BSE regularly. Information provided by health professionals via the media about correct BSE techniques and other health education opportunities may increase women's BSE practice [31].

Several factors based on the health belief model theory-greater confidence of women in their ability to perform BSE, higher health motivation and fewer barriers to BSE-were associated with performing BSE. However, confidence about performing BSE was the only factor that reached statistical significance. Similarly Yarbrough et al. [32] and MacDonald et al. [33] found that the health belief model did not predict breast cancer screening behaviour. The low variance on the perceived belief scales among our subjects may explain why the other health belief model scales could not predict breast cancer screening behaviour. The significant association between confidence and BSE performance in the previous year is consistent with the results of other studies $[29,34,35]$. This highlights the importance of introducing educational programmes to increase confidence and identifying barriers to BSE for Malaysian women. Intervention strategies should focus on teaching women how to make BSE a monthly habit.

Although a large proportion of the women in this study perceived breast cancer as a serious disease, most of them did not perceive themselves as being 


\begin{tabular}{|c|c|c|c|c|c|c|}
\hline Variable & $\beta$-coefficient & SE & Wald & $P$-value & OR & $95 \% \mathrm{Cl}$ \\
\hline \multicolumn{7}{|l|}{ Marital status } \\
\hline Single & & & & & 1 & \\
\hline Married & 0.244 & 0.520 & 0.221 & 0.638 & 1.28 & $0.46-3.53$ \\
\hline \multicolumn{7}{|l|}{ Age (years) } \\
\hline $20-30$ & & & & & 1 & \\
\hline $31-40$ & 0.55 & 0.370 & 0.022 & 0.883 & 1.06 & $0.51-2.18$ \\
\hline $41-50$ & -0.360 & 0.429 & 0.703 & 0.402 & 0.70 & $0.30-1.62$ \\
\hline$>50$ & -1.177 & 0.809 & 2.129 & 0.145 & 0.31 & $0.06-1.50$ \\
\hline \multicolumn{7}{|l|}{ Education } \\
\hline Diploma & & & & & 1 & \\
\hline Degree & 0.310 & 0.515 & 0.364 & 0.546 & 1.36 & $0.50-3.74$ \\
\hline Postgraduate & -0.450 & 0.819 & 0.302 & 0.583 & 0.64 & $0.13-3.17$ \\
\hline \multicolumn{7}{|l|}{ Income (RM) } \\
\hline$<3000$ & & & & & 1 & \\
\hline $3000-5000$ & -0.123 & 0.402 & 0.093 & 0.760 & 0.88 & 0.40-1.95 \\
\hline$>5000$ & 0.389 & 0.446 & 0.760 & 0.383 & 1.48 & $0.62-3.34$ \\
\hline \multicolumn{7}{|l|}{ Insurance } \\
\hline No & & & & & 1 & \\
\hline Yes & 0.105 & 0.314 & 0.112 & 0.738 & 1.11 & $0.60-2.06$ \\
\hline \multicolumn{7}{|l|}{ Regular health checkups } \\
\hline No & & & & & 1 & \\
\hline Yes & 1.291 & 0.354 & 13.325 & 0.001 & 3.64 & $1.82-7.27$ \\
\hline \multicolumn{7}{|c|}{ Family history of breast cancer } \\
\hline No & & & & & 1 & \\
\hline Yes & 0.912 & 0.506 & 3.249 & 0.071 & 2.49 & $0.92-6.71$ \\
\hline \multicolumn{7}{|c|}{ Personal history of breast disease } \\
\hline No & & & & & 1 & \\
\hline Yes & -0.156 & 0.849 & 0.034 & 0.854 & 0.86 & $0.16-4.52$ \\
\hline \multicolumn{7}{|l|}{ Heard about BSE } \\
\hline No & & & & & 1 & \\
\hline Yes & 0.626 & 1.119 & 0.313 & 0.576 & 1.87 & $0.21-16.8$ \\
\hline \multicolumn{7}{|l|}{ Perceived health status } \\
\hline Poor & & & & & 1 & \\
\hline Good & 1.467 & 0.958 & 2.346 & 0.126 & 4.34 & $0.66-28.3$ \\
\hline Satisfied & 1.522 & 0.946 & 2.587 & 0.108 & 4.58 & $0.72-29.3$ \\
\hline \multicolumn{7}{|c|}{ Undergoing clinical breast examination } \\
\hline No & & & & & 1 & \\
\hline Yes & 0.639 & 0.335 & 3.634 & 0.057 & 1.90 & $0.98-3.66$ \\
\hline \multicolumn{7}{|l|}{ Sources of information } \\
\hline Others & & & & & 1 & \\
\hline Doctors & 0.115 & 0.301 & 0.147 & 0.701 & 1.12 & $0.63-2.62$ \\
\hline \multicolumn{7}{|l|}{ Knowledge and beliefs } \\
\hline $\begin{array}{l}\text { Knowledge of breast } \\
\text { cancer \& screening }\end{array}$ & 0.073 & 0.026 & 8.240 & 0.004 & 1.08 & $1.02-1.13$ \\
\hline $\begin{array}{l}\text { Susceptibility to breast } \\
\text { cancer }\end{array}$ & 0.054 & 0.034 & 2.522 & 0.112 & 1.06 & $0.99-1.13$ \\
\hline $\begin{array}{l}\text { Seriousness of breast } \\
\text { cancer }\end{array}$ & 0.033 & 0.026 & 1.591 & 0.207 & 1.03 & 0.98-1.09 \\
\hline Benefits of BSE & 0.003 & 0.048 & 0.003 & 0.955 & 1.01 & $0.88-1.07$ \\
\hline Barriers to BSE & -0.010 & 0.041 & 0.061 & 0.806 & 0.91 & $0.92-1.00$ \\
\hline Confidence in BSE & 0.061 & 0.028 & 4.804 & 0.028 & 1.06 & $1.00-1.12$ \\
\hline Health motivation & 0.043 & 0.043 & 1.036 & 0.309 & 1.04 & $0.96-1.14$ \\
\hline
\end{tabular}

$S E=$ standard error; $O R=$ odds ratio; $C l=$ confidence interval; $R M=$ Malaysian ringgit. 
susceptible. This could be due to a lack of education on breast cancer and breast cancer screening practices. Health care personnel can provideinformationabout the magnitude and risk factors of breast cancer through public health education programmes. We found no significant relationship between women's beliefs about the seriousness of breast cancer and BSE practice. Previous studies have shown variable results about the relationship of perceived seriousness of breast cancer with BSE practices. While studies in the USA [30], Jordan [10] and Korea [29] suggested that screening increases with increased perceived seriousness of breast cancer, other studies in Turkey [11] and Hong Kong [36] found no association between perceived seriousness and BSE behaviors. Women need to be helped to avoid misconceptions about breast cancer and learn more about the benefits of early detection methods and timely treatment of breast cancer.

The majority of women in this study had positive beliefs about the benefits of BSE. Several studies have reported a significant positive relationship between perceived benefits of screening and BSE practice $[11,15,37]$, whereas others have found no significant effect $[10,35]$. This indicates a need for welldesigned awareness programmes that underline the benefits of preventive care and early screening.

Lack of knowledge, no time for BSE, embarrassment, fear of cancer diagnosis and perception of low susceptibility to breast cancer_were common barriers for performing BSE in the current study. Thus, further qualitative research is needed to identify barriers to BSE for Malaysian women.

Although a majority of the women in this study had high health motivation, this was not a predictor for BSE practice. According to previous studies using the health belief model, women who are more motivated to promote their health are more likely to perform BSE $[10,29,30]$. Similar to our finding, Secginli and Nahcivan found no association between health motivation and BSE practice [11].

Our results contrasted with previous findings suggesting that younger and well-educated women are more likely to practice breast cancer screening $[11,17]$. Women's family history of breast cancer was not a predictor for performing BSE also contrasted with previous studies $[7,10,11]$. It could be related to the small sample size and the low rate of family history of breast cancer among women in this study.

There were some limitations to this study. First, the participants were all secondary school teachers and were therefore unlikely to represent all Malaysian women and this influences the generalizability of the study results. Secondly, a self-administered questionnaire might lead to overestimation of cancer screening practices and use of health care services by subjects, a finding that could reduce the validity of the study. Thirdly, the study included a large number of young women. The inclusion of more women in the older age groups (particularly menopausal women), could yield a larger proportion of women who are currently practising BSE. Further research is recommended using a larger sample size with women of different ages, sociodemographic groups and occupational backgrounds. Nevertheless, the findings of this study could influence the planning of specific screening interventions and strategies for Malaysian women.

\section{Conclusions}

The fact that most breast cancers are found by patients themselves $[3,38]$ suggests that women should know about breast cancer symptoms and BSE techniques for early detection. Increased knowledge about breast cancer risk factors and screening methods can help women to change their lifestyle risk factors, decrease modifiable risk factors and actively practice breast cancer screening. The findings of this study point to an urgent need to increase Malaysian women's awareness about the value of BSE. The health belief model may be a useful framework for planning programmes for the early detection of breast cancer in Malaysian women.

\section{References}

1. National cancer registry, Malaysia 2003. The second report. Kuala Lumpur, Malaysia, Ministry of Health, 2003

2. Smith RA, Cokkinides V, Brawley OW. Cancer screening in the United States, 2009: a review of current American Cancer Society guidelines and issues in cancer screening. CA: $a$ Cancer Journal for Clinicians, 2009, 59:27-41.

3. Franco EL, Duarte-Franco E, Rohan TE. Evidence-based policy recommendations on cancer screening and prevention. Cancer Detection and Prevention, 2002, 26:350-361.

4. Smith RA, Cokkinides V, Eyre HJ; American Cancer Society. American Cancer Society guidelines for the early detection of cancer, 2003. CA: a Cancer Journal for Clinicians, 2003, 53:27-43.
5. Clinical practice guidelines for management of breast cancer. Kuala Lumpur, Malaysia, Ministry of Health, 2002.

6. Phillips JM, Wilbur J. Adherence to breast cancer screening guidelines among African-American women of differing employment status. Cancer Nursing, 1995, 18:258-269.

7. Salazar MK. Breast self-examination beliefs: a descriptive study. Public Health Nursing (Boston, Mass.), 1994, 11:49-56.

8. Miedema BB, Tatemichi S. Breast and cervical cancer screening for women between 50 and 69 years of age: what prompts women to screen? Women's Health Issues, 2003, 13:180-184.

9. Lu ZJ. Effectiveness of breast self-examination nursing interventions for Taiwanese community target groups. Oncology Nursing Forum, 1998, 25:1693-1701. 
10. Petro-Nustus W, Mikhail BI. Factors associated with breast selfexamination among Jordanian women. Public Health Nursing (Boston, Mass.), 2002, 19:263-271.

11. Secginli S, Nahcivan NO. Factors associated with breast cancer screening behaviours in a sample of Turkish women: a questionnaire survey. International Journal of Nursing Studies, 2006, 43:161-171.

12. Narimah A. Breast examination. In: Public Health Institute, Ministry of Health. Report of the second national health and morbidity survey conference. Kuala Lumpur, Ministry of Health, 1997:145-148.

13. Rosenstock IM. Why people use health services. Milbank Memorial Fund Quarterly, 1995, 44:94-127.

14. Champion VL. Instrument refinement for breast cancer screening behaviors. Nursing Research, 1993, 42:139-143.

15. Champion VL, Scott CR. Reliability and validity of breast cancer screening belief scales in African American women. Nursing Research, 1997, 46:331-337.

16. Pisani P, Bray F, Parkin DM. Estimates of the world-wide prevalence of cancer for 25 sites in the adult population. International Journal of Cancer, 2002, 97:72-81.

17. Hoeman SP, Ku YL, Ohl DR. Health beliefs and early detection among Chinese women. Western Journal of Nursing Research, 1996, 18:518-533.

18. Straughan PT, Seow A. Attitudes as barriers in breast screening: a prospective study among Singapore women. Social Science \& Medicine, 2000, 51:1695-1703.

19. Juon HS, Seo YJ, Kim MT. Breast and cervical cancer screening among Korean American elderly women. European Journal of Oncology Nursing, 2002, 6:228-235.

20. Legg JS, Fauber TL, Ozcan YA. The influence of previous breast cancer upon mammography utilization. Women's Health Issues, 2003, 13:62-67.

21. Parsa $\mathrm{P}$ et al. Knowledge and behaviors on breast cancer screening among female teachers in Selangor, Malaysia. Asian Pacific Cancer Prevention Journal, 2008, 9:271-278.

22. Nunnally J, ed. Psychometric theory. New York, McGraw-Hill, 1967.

23. Parsa P et al. Reliability and validity of Champion's Health Belief Model Scale for breast cancer screening among Malaysian women. Singapore Medical Journal, 2008, 49:897-903.

24. Jarvandi $\mathrm{S}$ et al. Beliefs and behaviours of Iranian teachers toward early detection of breast cancer and breast self-examination. Public Health, 2002, 116:245-249.

25. Yanni-Seif N, Aziz M. Effect of breast self examination training program on knowledge, attitude and practices of a group of working women. Journal of the Egyptian National Cancer Institute, 2000, 12:105-115.

26. Rashidi A, Rajaram SS. Middle Eastern Asian Islamic women and breast self-examination. Needs assessment. Cancer Nursing, 2000, 23:64-70.

27. Ajayi IO, Adebamowo CA. Knowledge, belief, attitudes towards breast cancer in Southwestern Nigeria. Cancer Strategy, 1999, 1:20-24.

28. Aliabadi-Wahle S. Training in clinical breast examination as part of a general surgery core curriculum. Journal of Cancer Education, 2000, 15:10-13.

29. Han Y, Williams RD, Harrison RA. Breast cancer screening knowledge, attitudes, and practices among Korean American women. Oncology Nursing Forum, 2000, 27:1585-1591.

30. Champion VL, Menon U. Predicting mammography and breast elf-examination in African American women. Cancer Nursing, 1997, 20(5):315-322.

31. Kalichman SC, Williams E, Nachimson D. Randomized community trial of a breast self-examination skills-building intervention for inner-city African-American women. Journal of the American Medical Women's Association, 2000, 55:47-50.

32. Yabroff KR, Mandelblatt JS. Interventions targeted toward patients to increase mammography use. Cancer Epidemiology, Biomarkers \& Prevention, 1999, 8:749-757.

33. McDonald PA et al. Perceptions and knowledge of breast cancer among African-American women residing in public housing. Ethnicity \& Disease, 1999, 9:81-93.

34. Erblich J, Bovbjerg DH, Valdimarsdottir HB. Psychological distress, health beliefs, and frequency of breast self-examination. Journal of Behavioral Medicine, 2000, 23:277-292.

35. Smiley MR et al. Comparison of Florida Hispanic and nonHispanic Caucasian women in their health beliefs related to breast cancer and health locus of control. Oncology Nursing Forum, 2000, 27:975-984.

36. Fung SY. Factors associated with breast self-examination behaviour among Chinese women in Hong Kong. Patient Education and Counseling, 1998, 33:233-243.

37. Bazargan $\mathrm{M}$ et al. Mammography screening and breast self examination among minority women in public housing projects: the impact of physician recommendation. Cellular and molecular biology (Noisy-le-Grand, France), 2003, 49(8):1213-1218.

38. Aspinall V. An effectiveness way to reduce mortality. Screening for malignant breast disease. Professional Nurse (London, England), 1991, 6:283-287. 